\title{
AVALIAÇÃO INSTITUCIONAL E ELABORAÇÃO DO PLANO GESTOR ESCOLAR
}

Maria Luiza de Sousa Pinha, José Camilo dos Santos Filho

Mestrado em Educação da Universidade do Oeste Paulista - UNOESTE - Presidente Prudente. E-mail: malupinha3@yahoo.com.br

\section{RESUMO}

O objetivo da presente pesquisa foi verificar se os resultados e conclusões da avaliação interna e externa da escola têm subsidiado a elaboração do Plano de Gestão Escolar. Numa abordagem qualitativa, empregou-se como procedimento o estudo de caso de uma escola estadual do Estado de São Paulo. Para a coleta, foram utilizadas observação, pesquisa documental e entrevista semiestruturada. Foram sujeitos da pesquisa membros dos segmentos escolares representados no Conselho Escolar. Os resultados da pesquisa indicaram que as avaliações internas e externas constam do Plano Gestor, mas não foram seguidas de análise, interpretação, reflexão ou proposta de ação. Verificou-se o ranço histórico centralizador na elaboração do Plano Gestor que ficou a cargo da equipe gestora, os executores do processo de elaboração, execução, acompanhamento e avaliação com a participação dos professores. A avaliação diagnóstica não representou uma leitura transparente da realidade escolar, pois nem todos os membros do Conselho Escolar participaram dela.

Palavras-chave: Avaliação Institucional da escola; Avaliação interna da escola; Avaliação externa da escola; Plano de Gestão Escolar; Qualidade do Ensino.

\section{INTRODUÇÃO E OBJETIVO}

Ao realizar esta pesquisa procuramos por meio da avaliação institucional - avaliação interna e avaliação externa -, buscar a totalidade da instituição, isto é, uma avaliação escolar como concebem vários dos autores citados na fundamentação teórica deste estudo, ou seja, como um processo contínuo, tendo em vista a melhoria da qualidade do ensino.

O Plano de Gestão Escolar, objeto de nosso estudo, foi um dos documentos considerado de grande relevância para nossas análises e confronto com as falas dos entrevistados quanto à sua elaboração e à utilização da avaliação interna e externa da escola para subsidiar a sua construção. É um documento com característica dinâmica na medida em que exerce acompanhamento e controle de todo o processo escolar durante seu quadriênio. Este documento traça o perfil da escola conferindo-lhe sua identidade, define as intenções de todos os envolvidos na comunidade escolar, gerencia as ações, operacionaliza o Projeto Pedagógico avaliando periodicamente seus objetivos e metas, e define as diretrizes dos Planos de Ensino, como estabelece o Parecer CEE no 67/69 e o artigo 24 do Regimento Escolar. 
Levando em consideração as afirmações acima, procuramos analisar os documentos dos Planos Gestores (versão 2007 a 2010 e versão 2011 a 2014), como foram construídos ao longo dos anos, se apenas como um documento ou um registro, ou se foi realizada uma análise do plano anterior no que concerne ao diagnóstico da escola. Buscamos nos documentos identificar o diagnóstico da escola e as propostas de ações a serem executadas.

Nosso propósito, ao analisar o Plano Gestor Escolar 2011-2014, foi indagar se, na prática, além de utilizar os resultados da avaliação interna e externa, se alicerçou uma administração participativa e coletiva. Como observam Ferri, Macedo e Santos (2012, p. 235),

[...] avaliação diagnóstica permite à equipe levantar as fragilidades e potencialidades da instituição para, em seguida, apontar os caminhos, definir estratégias e propor ações para a superação dos problemas e incremento das potencialidades.

Mais especificamente, o objetivo dessa pesquisa foi verificar se os resultados e conclusões da avaliação interna e externa da escola (SAEB, SARESP, IDEB e IDESP) subsidiaram a elaboração do Plano de Gestão Escolar. Entendemos que a escola é uma instituição social que se encontra em transformação que busca nos resultados da avaliação interna e externa, no coletivo, na participação, as respostas, os caminhos para as suas necessidades e expectativas no dia a dia do cotidiano escolar.

Consideramos que a avaliação interna e externa da instituição é instrumento de grande utilidade e poderá fornecer informações relevantes acerca das diferentes dimensões da escola a fim de prestar contas à sociedade e aprimorar o ensino, sempre em busca da melhoria da escola.

\section{METODOLOGIA}

Trata-se de um estudo de caso de uma pesquisa segundo a abordagem qualitativa realizado em uma escola estadual de educação básica. Este artigo se refere apenas a um dos aspectos de pesquisa mais ampla concluída recentemente realizada numa escola estadual do Estado de São Paulo.

A escola participante da pesquisa é bastante tradicional na cidade, contando com um total de 843 alunos, 64 professores e 14 funcionários, com sua jurisdição na Diretoria de Ensino da Região de Ourinhos (DERO). Oferece cursos de Ensino Fundamental (Ciclos II) e Ensino Médio, ministrados em horários diferenciados e em três turnos diferentes para atender à sua clientela nos períodos matutino, vespertino e noturno de segunda-feira a sexta-feira. 
Participaram da pesquisa: quatro gestores (diretor de escola, vice- diretor de escola, coordenadores do Ensino Fundamental e do Ensino Médio), seis professores, dois funcionários, quatro pais de alunos e quatro alunos, todos membros do Conselho Escolar da Escola. Os sujeitos participantes tiveram suas identidades preservadas e por isso foram identificados apenas por códigos.

A coleta de dados foi realizada por meio de observação, entrevista semiestruturada e análise documental. Os instrumentos de coleta de dados tiveram a aprovação do Comitê de Ética em Pesquisa (CEP) da Universidade cujo número de protocolo foi 638.

As entrevistas semiestruturadas foram feitas com o objetivo de coletar dados, informações e significações contidas nas falas dos participantes. No roteiro de entrevistas para o Plano Gestor Escolar foram consideradas as seguintes dimensões: Participantes da elaboração, forma de utilização dos dados da avaliação interna e externa para elaboração, reformulação e acompanhamento do Plano Gestor; participação do Conselho Escolar na avaliação interna e nas análises das avaliações da escola. A análise dos documentos permitiu a detecção de dados que necessitavam ser explorados complementando ou confirmando informações. Foram analisados: Regimento Escolar, Planos de Gestão Escolar (versões 2007 a 2010 e 2011 a 2014), atas das reuniões do Conselho escolar, relatório de autoavaliação diagnóstica da escola resultante das avaliações internas e externas da escola. Foi elaborado um roteiro de observação para o acompanhamento do ambiente escolar, reuniões do Conselho Escolar e de outras reuniões. A observação agregou impressões, registros de fenômenos e contato direto com as pessoas entrevistadas.

\section{RESULTADOS}

Considerando os aspectos da avaliação, acompanhamento e elaboração, podemos constatar que na construção do Plano de Gestão foram utilizados os resultados do desempenho dos alunos e da escola na avaliação interna e externa (SARESP, IDESP e IDEB), porém, não ficou claro se, na prática, foi alicerçado numa administração participativa e coletiva, em que as decisões teriam sido tomadas democraticamente por todos os representantes da comunidade escolar.

Constatamos que a equipe gestora, com a colaboração dos professores, vem desempenhando sua responsabilidade técnica de elaborar, acompanhar, avaliar, planejar e replanejar o Plano Diretor da escola. No entanto, as entrevistas e a análise das atas das reuniões do Conselho Escolar revelaram que os pais, alunos e funcionários, como representantes de suas 
respectivas categorias no conselho, não foram informados nem participaram do processo de elaboração e de aprovação do Plano Diretor. A análise das atas do Conselho Escolar evidenciou a ausência de atas de aprovação do Plano Diretor pelo referido conselho, o que vem confirmar a razão da ignorância dos membros do conselho quanto à participação na elaboração do Plano Diretor e quanto à utilização da avaliação interna e externa como subsídio para a construção do plano. A avaliação diagnóstica realizada não representou uma leitura transparente da realidade escolar já que somente teve a participação da equipe gestora e dos professores.

O Plano Gestor não correspondeu aos princípios de participação do coletivo, no qual uma gestão democrática apontasse os obstáculos a serem superados pela comunidade escolar e os caminhos para avançar na transformação da escola e das práticas centralizadoras e autocráticas de tomada de decisão. No entanto, observamos um avanço da equipe gestora que, apesar de ainda centralizadora, apresenta uma rotina de reflexão no processo de execução, acompanhamento e avaliação do Plano Gestor, embora ainda longe do ideal de envolvimento de toda a comunidade escolar nesse processo.

\section{DISCUSSÃO}

Buscamos no Plano de Gestão ações intencionais que foram traçadas pelas necessidades apontadas pela avaliação diagnóstica elaborada pelo coletivo da escola. Como afirmam Ferri, Macedo e Santos (2012, p. 235), “[...] o plano de gestão, também fruto do coletivo, apresenta-se como um percurso situacional e operacional que possibilita uma avaliação diagnóstica mais aprofundada da escola". O que percebemos é que o Plano Gestor dessa escola, tanto na versão 2007 a 2010, como na atual (2011 a 2014), foi construído ao longo dos anos como um documento ou um registro baseado na análise do plano anterior no que concerne ao diagnóstico da escola.

Considerando que compete à direção da escola garantir a elaboração, execução, acompanhamento e avaliação do Plano Gestor, constatamos que a equipe dos gestores vem cumprindo sua responsabilidade técnica nessa tarefa. Como se trata de início de mais um quadriênio, pudemos observar que todas as segundas-feiras, no período noturno, a equipe gestora se reunia para avaliação e elaboração do Plano Gestor, como recomenda Dalmas (1994, p. 107):

[...] a avaliação situa o grupo no processo, propiciando a possibilidade de um julgamento mais concreto da caminhada realizada, com o conhecimento crítico da situação em que se encontra e conduz ao estabelecimento de prospectivas com relação ao restante do processo. 
Vimos que os professores, como membros do corpo técnico da escola, participaram da elaboração do Plano Gestor da escola, bem como de seu planejamento e replanejamento, nos momentos estabelecidos no calendário escolar. As falas, principalmente as dos professores, revelaram que essa participação se realiza por meio de convocações, o que se coaduna com a recomendação de Feitas (2005b, p. 928):

Cada escola deve tornar-se um centro de reflexão sobre si mesma, sobre o seu futuro. [...] não é apenas o professor que deve ser reflexivo [...] toda a escola necessita ser reflexiva, gestores (direção e coordenação), professores, funcionários, alunos e pais de alunos.

Considerando a abrangência da sugestão deste autor, buscamos verificar se os funcionários, alunos e pais de alunos, como membros do Conselho de Escola e de acordo com o Regimento Escolar, participaram na elaboração e aprovação do Plano Gestor a ser encaminhado para homologação pelas instâncias superiores da administração do sistema escolar. Neste caso, constatamos desinformação e não participação desses atores nesse processo e, sequer participação na aprovação do plano no colegiado da escola, como comprova a ausência de atas de sua aprovação nessa instância. Isso mostrou que a dimensão pública do Plano Gestor não está sendo concretizada na realidade porque, para que isso aconteça, terá que envolver na sua elaboração e aprovação não só os gestores escolares (direção e coordenação) e os professores, mas também os demais representantes do conselho escolar (funcionários, alunos e pais de alunos).

Como afirma Freitas (2004, p. 928): “[...] os gestores têm um importante papel mobilizador a cumprir" para que a escola tenha um processo interno de reflexão conduzido pela sua comunidade interna. O papel do gestor é de condutor do processo e não poderia ter deixado de fora os membros do Conselho de Escola (funcionários, alunos e pais) na participação na elaboração do Plano Gestor, já que esse é a peça gerenciadora da Proposta Pedagógica e dos Planos de Ensino.

No que se refere às avaliações praticadas nessa instituição de ensino, constam em seu Plano Gestor atual (2011-2014) as avaliações externas e internas. Destacam-se primeiramente no Plano os resultados das avaliações externas da escola (SARESP, IDESP, IDEB e ENEM) e os resultados do desempenho na avaliação interna. No entanto, tais dados não foram seguidos de qualquer análise ou interpretação, nem de qualquer reflexão ou proposta de ação, com base nos resultados da avaliação. 
Para Soares, Alves e Mari (2003, p. 59), “a avaliação começa com o conhecimento dos resultados da escola, mas só se concretiza ao produzir informação útil para a modificação dos processos internos específicos". De nada adianta conhecer esses resultados se não forem transformados em informação útil para construir conhecimentos sobre a própria escola e realizar um processo de compreensão e transformação da realidade escolar, como propõe o Regimento escolar, no seu artigo 29, ao recomendar que a avaliação da instituição seja realizada por meio de procedimentos internos e externos objetivando análise, orientação e correção.

A utilização dos dados da avaliação interna e externa na elaboração e atualização do Plano Gestor pode fornecer subsídios para sua avaliação formativa, contribuindo para a reflexão, discussão e correção de rumos do plano. Como observam Dias Sobrinho e Balzan (2008, p. 66), "[...] o processo de elaboração de conhecimento e de crítica, que constitui a avaliação, também produz no interior de seu próprio desenvolvimento a tomada de consciência da necessidade de transformação do processo [...] de avaliação". Portanto, é necessário priorizar a avaliação formativa e reafirmar o valor do processo e das relações que irão dar consistência ao esforço coletivo fazendo da instituição escolar um local não só de reflexão, mas também de significados. Salientamos que, a despeito de ações para promoção de informação e conhecimento sobre o Plano Gestor junto aos funcionários, alunos e pais de alunos, não foi constatado nenhum envolvimento desses segmentos nas reuniões de planejamento e replanejamento. Cabe à escola a promoção dessa participação.

Considerando o Diagnóstico da Escola quanto às ações propostas, essas aparecem sem intencionalidade, já que não houve o envolvimento de parte da comunidade escolar nas decisões e informações escolares não proporcionando a esses que desenvolvam vínculos, responsabilidades, consciência crítica e participativa, propiciando cada vez mais a desconstrução da identidade escolar. O que verificamos é que o diagnóstico não representa uma leitura transparente da realidade da escola, como observa Ferri, Macedo e Santos (2012, p. 236),

O diagnóstico compreendido como o retrato da realidade, permite a equipe reconhecer suas necessidades ao propiciar uma reflexão clara e verdadeira, partindo do contexto global para uma análise apurada da realidade escolar e utilizando os dados das avaliações realizadas na própria escola, das avaliações externas e da autoavaliação institucional.

O Plano Gestor da escola versão 2011 a 2014 só terá êxito se passar a ser um documento capaz de avaliar periodicamente as metas e ações propostas, bem como se conseguir orientar e acompanhar os Planos de Ensino, ao longo do seu quadriênio, bem como a Proposta Pedagógica 
da escola garantindo o alcance dos objetivos e metas traçadas, o trabalho coletivo e a melhoria da qualidade do ensino na unidade escolar. Para Libâneo (2004, p. 149), "Um plano ou um projeto é um esboço, um esquema que representa uma ideia, um objetivo, uma meta, uma sequência de ações que irão orientar a prática".

\section{CONCLUSÃO}

A revisão de literatura permitiu-nos o embasamento teórico do estudo e forneceu-nos importantes informações acerca do tema em questão, dando-nos a oportunidade de tecer considerações no que tange à avaliação institucional como instrumento de monitoramento e aprimoramento da gestão da escola pública de educação básica.

O Plano de Gestão representa para os gestores e professores o documento de maior importância dentro da escola por seu valor legal. A escola se refere a ele como o documento normativo que tem o dever de ser homologado, portanto, a prestação de contas aos seus superiores. No entanto, notamos nesse documento um sentido burocrático, mas não o de compromisso com a melhoria da qualidade do ensino. Como documento, não correspondeu aos princípios de participação do coletivo, onde uma gestão democrática apontasse os obstáculos a serem superados que pudessem, por meio da comunidade escolar, avançar na prática para a transformação e superação dos entraves nas tomadas de decisão de uma administração centralizadora e autocrática. Por outro lado, vemos um avanço da equipe gestora que, apesar de centralizadora, apresenta uma rotina de reflexão na elaboração e acompanhamento do Plano Gestor, embora o desejável fosse o envolvimento de todos os membros do conselho escolar.

Os dados contidos no Plano de Gestão sobre avaliação interna e externa constituem informações sobre os resultados das avaliações que, por si só, não significam nada se a escola não realizar uma avaliação sistêmica de sua realidade. Como documento, deveria conter e contemplar as intenções de todos os envolvidos, pois também é fruto do coletivo e atender às dimensões política e técnica. A elaboração do Plano ficou exclusivamente a cargo da equipe gestora, o que demonstra seu ranço histórico centralizador e burocrático. No entanto, a escola precisa incorporar o novo espírito descentralizador e democrático da nova LDB. Observamos que a democracia, a participação, a transparência e a clareza das regras ainda é um ideal distante do cotidiano escolar.

Acreditamos, por fim, que a autoavaliação institucional não é apenas uma ferramenta pedagógica, mas também um instrumento político da mais alta relevância para a gestão escolar, na medida em que permite dar transparência aos resultados dos serviços educacionais prestados e 
ofertados pela rede pública e transformar a qualidade desses serviços, mediante ações voltadas para resultados que demonstrem a melhoria da qualidade do ensino.

\section{REFERÊNCIAS}

DALMAS, A. Planejamento participativo na escola. Petrópolis: Vozes, 1994.

DIAS SOBRINHO, J.; BALZAN, N. C. Avaliação institucional: teorias e experiências. São Paulo: Cortez, 2008.

FERRI, L. M. C. G.; MACEDO, M. E. C. M.; SANTOS, C. M. Projeto educativo, planejamento participativo e gestão escolar. In: SANTOS FILHO, J. C. (Org.). Projeto educativo escolar. Petrópolis: Vozes, 2012, p. 219-245. (no prelo).

FREITAS, L. C. et al. Dialética da inclusão e da exclusão: por uma qualidade negociada e emancipadora nas escolas. In: GERALDI, C. M. G.; RIOLFI, C. R.; GARCIA, M. F. (Orgs.). Escola viva: elementos para a construção de uma educação de qualidade social. Campinas: Mercado e Letras, 2004.

FREITAS, L. C. Qualidade negociada: avaliação e contra-regulação na escola pública. Educação e Sociedade, Campinas, v. 26, n. 92, p. 911-933, (Especial) out., 2005. Disponível em: <http://www.cedes.unicamp.br>. Acesso em: 5 mar. 2011.

LIBÂNEO, J. C. Organização e gestão da escola: teoria e prática. Goiânia: Alternativa, 2004.

SANTOS FILHO, J. C. (Org.). Projeto educativo escolar. Petrópolis: Vozes, 2012, no prelo.

SOARES, J. F.; ALVES, M. T. G.; MARI, F. A. T. Avaliação de escolas de ensino básico. In: FREITAS L. C. (Org.). Avaliação de escolas e universidades. Campinas: Komedi, 2003. 